\title{
EDITORIAL
}

\section{The downfalls of BMI-focused policies}

\author{
International Journal of Obesity (2016) 40, 729-730; \\ doi:10.1038/ijo.2016.18
}

Numerous healthcare policies have been proposed to reduce the health burden associated with obesity in the United States through various aspects of obesity treatment and prevention. Many of these policies utilize body mass index $\left(\mathrm{BMI}, \mathrm{kg} \mathrm{m}^{-2}\right)$, as the instrument of assessment for implementation and evaluation. Traditional nomenclature defines obesity as a $\mathrm{BMI} \geqslant 30$, and overweight as a BMI between 25 and 29.9; these BMI ranges were developed by assessing metabolic risk affiliated with various ranges.

Using BMI to evaluate policy is simple and intuitive, as BMI provides reasonable specificity and sensitivity as a marker of health in the general population. ${ }^{1}$ However, BMI does not provide high predictive ability to determine an individual's current health status. In this issue, the analysis of 2005-2012 National Health and Nutrition Examination Survey data by Tomiyama et al., ${ }^{2}$ demonstrated this, and they determined that solely using BMI as a risk indicator of health would incorrectly classify the health of an estimated 75 million US adults.

In such instances, the use of BMI as the single assessment tool may result in the policies that are counter-productive and discriminatory. The Equal Employment Opportunity Commission recently proposed a rule allowing a penalty of up to $30 \%$ of an overweight employee's health insurance premium if the employee does not lose weight and reach a lower BMI risk category. If the objective of this policy is to penalize those with ill health in order to incentivize them to improve it, this policy may penalize the substantial number of employees who are overweight or obese and do not have ill health and comorbidities. This policy may also fail to incentivize employees who are normal weight, and have metabolic disorders, to improve their health.

BMI-based policies may have other unintended consequences that make them counterproductive as well. First, policies that penalize or punish individuals for their $\mathrm{BMI}$, or for not reducing their weight, are perceived by those with obesity as stigmatizing. ${ }^{3}$ As a result, BMI-based policies can be not only unhelpful, but also harmful., 3

BMI-based policies may also be unproductive as they often seek unrealistic weight loss. First, individuals may not have access to adequate tools for weight loss, as most health insurance policies do not cover the evidence-based obesity treatment modalities that ensure successful weight loss outcomes. ${ }^{5}$ Then, even if covered by a patient's policy, most treatments (other than bariatric surgery, which is reserved for patients with morbid obesity or patients with obesity and comorbidities) produce $5-10 \%$ weight loss on average. ${ }^{6}$ This amount of weight loss may be insufficient to move a patient to a lower-risk BMl category, leaving individuals who have lost weight still in the category receiving a penalty, despite the implementation of evidencebased treatment. A multitude of studies demonstrate that the BMI reductions expected from BMI-based policies are often overstated and unrealistic.

Finally, evidence suggests that some lifestyle interventions may reduce comorbidities independent of a change in BMI. For example, exercise alone, without a change in BMI, is sufficient to improve outcomes such as physical fitness, hepatic lipid content, blood pressure and insulin sensitivity. ${ }^{7-9}$ If health is truly the focus of policies, and the health risk associated with high-risk BMI can be reduced from changes in lifestyle habits alone, the relevance of BMI-based policies for some outcomes is questionable.

Obesity is a chronic and complex disease, and the relationship between body fat and health is complex. Recognizing this, the definition of 'obesity' by The Obesity Society does not rely on BMI, and says so explicitly. ${ }^{10}$

'We define obesity as an excess of body fat. It may be of either total body fat or a particular depot of body fat. The excess may even be in the morphology and function of body fat such that, for example, adipocytes, independent of total fat mass or fat mass distribution, are excessively enlarged. The adverse health consequences of accumulation of enlarged visceral or other adipocytes may tentatively be accounted for by enhanced secretion of most products of adipocytes that act as endocrine and paracrine factors on other cells, as well as the reduced production of adiponectin (27). Note that we do not define obesity as a BMI greater than or equal to $30 \mathrm{~kg} / \mathrm{m}^{2}, 10$

If policy makers seek to improve health, it is critical to recognize that obesity is not simply an issue of body weight. It is a life-long, chronic condition that requires persistent, evidence-based treatment. As has succeeded with other diseases, policy makers should focus on strategies that truly improve the quality of life and health of people with obesity. These may include lifestyle interventions that incentivize physical activity, reduced energy intake and encourage healthy habits, rather than a number on a scale. Due to the unintended consequences of BMI-based policies, there are many instances in which they may do more harm than good.

\section{CONFLICT OF INTEREST}

The author declares no conflict of interest.

EJ Dhurandhar

Department of Kinesiology and Sports Management,

Texas Tech University, Lubbock, TX, USA

E-mail: emily.dhurandhar@ttu.edu

\section{REFERENCES}

1 Bray GA, Bouchard C. Handbook of Obesity - Volume 2: Clinical Applications. Taylor \& Francis Group: Boca Raton, FL, USA, 2014.

2 Tomiyama AJ, Hunger JM, Nguyen-Cuu J, Wells C. Misclassification of cardiometabolic health when using body mass index categories in NHANES 2005-2012. Int J Obes (Lond) 2016; 40: 883-886.

3 Tannenbaum D, Valasek CJ, Knowles ED, Ditto PH. Incentivizing wellness in the workplace: sticks (not carrots) send stigmatizing signals. Psychol Sci 2013; 24: 1512-1522.

4 Robinson E, Hunger JM, Daly M. Perceived weight status and risk of weight gain across life in US and UK adults. Int J Obes (Lond) 2015; 39: 1721-1726.

5 Kyle T, Nadglowski J, Stanford FC. Consumers Report That Health Insurance Does Not Often Cover Obesity Treatment, Even When Wellness Programs Target BMI. Obesity Week: Los Angeles, CA, USA, 2015.

6 Jensen MD, Ryan DH, Donato KA, Apovian CM, Ard JD, Comuzzie AG et al. Guidelines (2013) for managing overweight and obesity in adults. Obesity (Silver Spring) 2014; 22(S2): S1-S410. 
7 Hallsworth K, Fattakhova G, Hollingsworth KG, Thoma C, Moore S, Taylor R et al. Resistance exercise reduces liver fat and its mediators in non-alcoholic fatty liver disease independent of weight loss. Gut 2011; 60: 1278-1283.

8 Nassis GP, Papantakou K, Skenderi K, Triandafillopoulou M, Kavouras SA, Yannakoulia $M$ et al. Aerobic exercise training improves insulin sensitivity without changes in body weight, body fat, adiponectin, and inflammatory markers in overweight and obese girls. Metabolism 2005; 54: 1472-1479.
9 Dengel DR, Galecki AT, Hagberg JM, Pratley RE. The independent and combined effects of weight loss and aerobic exercise on blood pressure and oral glucose tolerance in older men. Am J Hypertens 1998; 11: 1405-1412.

10 Allison DB, Downey M, Atkinson RL, Billington $\mathrm{CJ}$, Bray GA, Eckel RH et al. Obesity as a disease: A white paper on evidence and arguments commissioned by the Council of the Obesity Society. Obesity (Silver Spring) 2008; 16: $1161-1177$. 